\title{
The Swiss Franc Exchange Rate and Deviations from Uncovered Interest Parity: Global vs Domestic Factors ${ }^{a}$
}

\author{
Mathias Hoffmann and Rahel Suter ${ }^{b}$
}

JEL-Classification: F31, F36, G12

Keywords: currency risk, exchange rate, save haven effects, uncovered interest parity (UIP)

\section{Introduction}

The 10th anniversary of the new monetary policy framework of the SNB is a good opportunity to look at the changing role of the Swiss franc as an international currency. The last decade was characterized by tidal change around the world, including catastrophic turmoil (Sept. 11th attacks), major transformations of the international financial system (such as the creation of the euro) and an (until recently) continued decrease in macroeconomic volatility. All of these developments could plausibly have affected the classical role of the Swiss franc as a safe haven. Whether the franc is a safe haven clearly has major implications from the point of view of monetary policy making: in a small open economy such as Switzerland, variation in the nominal exchange rate is an important factor in determining domestic inflation (see Rотн, 2008). To what extent monetary policy can impact the exchange rate if needed is therefore a crucial determinant of its effectiveness. A safe haven currency is likely to be buffeted mainly by global factors in times of worldwide turbulence which could limit the effectiveness of monetary policy. This paper explores the relative role of global and country-specific factors in the Swiss franc exchange rate. Specifically we seek to understand if the impact of global shocks on the bilateral Swiss franc exchange rate vis-àvis major currencies has been varying over time - possibly leading to safe haven behavior - and what the factors driving this variation may be.

a The authors are grateful to comments and discussions obtained during the conference. Special thanks go to Tommaso Mancini Grifolli and Kevin Ross for their insightful and stimulating discussions of the paper.

b Both authors are at University of Zurich, Institute for Empirical Research in Economics, Chair of International Trade and Finance, Zuerichbergstrasse 14, CH-8032 Zurich /Switzerland. E-mail: mathias.hoffmann@iew.uzh.ch and rahel.suter@access.uzh.ch URL: www.iew.uzh.ch/itf. 
Academic research dedicated to the save haven phenomenon is relatively sparse. RANALDO and SöDERLIND (2008) is one of the few recent contributions that have systematically sought to identify safe haven characteristics in a cross-section of major currencies. They conclude that the Swiss franc, the yen, and to a limited extent also the euro display safe haven characteristics while the dollar and the pound show no such behaviour.

In a series of recent papers, Kugler and Weder $(2004,2005)$ have documented what they call the Swiss interest rate puzzle, the fact that excess returns on the Swiss franc over the last seventy years are persistently negative, marking a gross violation of uncovered interest parity. They ascribe this pattern to a peso problem, i.e. to safe haven characteristics but conclude (in WedER and KugLer, 2009) that evidence for a Swiss interest rate island (Kugler and Weder, 2002) is much less clear-cut in the last ten years than it used to be before. This is an important point of departure for our analysis: the first ten years of the new operating framework coincide with this "disappearance of the island". It is therefore a timely question to ask whether the safe haven characteristic has disappeared for good or whether the strength of the phenomenon could itself be time varying and dependent on the global environment.

LENZ and SAVioz (2009) examine the role of monetary policy shocks for the determination of the Swiss Franc exchange rate in a structural VAR framework. They do not explicitly distinguish between global and county-specific shocks to the exchange rate but, consistent with our conjecture here, they find that the relative contribution of monetary policy shocks has been varying over time.

Until recently, the notion that departures from uncovered interest parity could be driven by currency risk premia was viewed with considerable skepticism by many in the economics profession (see the survey by EnGEL, 1996). ${ }^{1}$ The seminal work by Lustig and VerdelHan (2007) has helped to initiate a gradual change of this view. Lustig and Verdelhan argue that excess returns on currency portfolios that are formed on the size of the interest rate differential towards the US dollar can be explained by a version of the consumption-based capital asset pricing model. In more recent work, Lustig, Roussanov and Verdelhan (2009) (henceforth LRV) propose a linear factor model in which the spread between the return on the highest and lowest interest rate portfolios - a global carry trade factor - helps explain a significant share in the cross-sectional variation of

1 Since the safe have phenomenon is inextricably linked to currency risk premia, this may also help explain the sparsity of this particular branch of the literature. 
currency returns. We interpret a currency's exposure to this factor as a measure of a currency's global or 'safe haven' component. As in LRV we argue that crosscountry differences in the exposure to the global factor can help explain differences in the size of the departure from uncovered interest parity (UIP). Different from LRV however, our focus is on single currency pairs (and not on currency portfolios) and we allow the strength of a currency's exposure to the global factor to vary over time as a function of the interest rate differential. We apply this framework to monthly exchange rates and interest rate differentials for the Swiss franc vis-à-vis five other major currencies - the US dollar, the Canadian dollar, the Deuschmark/euro, the Japanese yen and the British pound - over the period 1990:6-2009:4. Our main results are as follows:

Over the last twenty years, the Swiss franc has displayed safe haven characteristics in its behaviour vis-à-vis the US and Canadian dollar and the pound. It has not played such a role vis-à-vis the euro and the Japanese yen. As regards the euro, this may be explained by the rise of the single European currency as a major international and reserve currency itself. As regards the yen, our findings could be explained by the fact that next to the franc, the yen is another preferred funding currency in the global carry trade.

However, the safe haven characteristic - and with it the role of global factors for the exchange rate - has varied considerably over the sample period. Global factors were important in some episodes - specifically during the late 1990s (the Asian crisis and its aftermath) - and have proven to be very persistent for the average valuation of the Swiss franc against other currencies. But the exposure of the Swiss currency to global shocks appeared somewhat more subdued over the best part of the last ten years. Our analytical framework allows an interpretation of this fact: in our setup, differences in the exposure to global shocks are reflected in interest rate differentials. The globally low interest rate environment of the last decade has substantially mitigated differences in the exposure to global shocks among the major currencies studied here. However, sufficiently large global shocks could again lead to considerable cross-country heterogeneity in the responses to such shocks in the future. This in turn could quickly revive safe haven behavior in individual currency pairs and may suggest that the safe haven property is actually latent. The appreciation of the franc in the aftermath of the subprime crises seems to support this view - the Swiss interest rate island may have temporarily disappeared only because economic conditions were globally benign.

Here is the outline of the remainder of this paper: in the next section we adapt the framework of Lustig, Roussanov and Verdelhan (2009) to discuss the relative role of global and country-specific factors in explaining the Swiss franc 
exchange rate. In Section 3 follows a discussion of the data set, Section 4 presents the empirical results. Section 5 provides some further discussion of our findings and concludes.

\section{Global and Country-Specific Factors in Currency Returns}

We start by presenting a simplified version of the framework by Lustig, RousSANOV and Verdalhen (2009) and then adapt it to study the dynamics of the Swiss franc exchange rate. Our point of departure is the recognition that in complete financial markets, the exchange rate change is the difference between the (logarithmic) home and foreign discount factors:

$$
\Delta s_{t+1}^{k h}=m_{t+1}^{h}-m_{t+1}^{k}
$$

where $\Delta s_{t+1}^{k h}$ is the rate of change of the spot exchange rate measured in units of foreign (country $k$ ) currency per unit of home currency and $m^{b}\left(m^{k}\right)$ denotes the logarithmic home (foreign) discount factor. ${ }^{2}$ We can think of differences between home and foreign discount factors as the outcome of frictions and goods markets (e.g. the presence of notradeable goods as in BACKUS and SMITH, 1993) that, however, do not reflect a failure to share financial risk. We posit the existence of a linear factor structure for the cross-section of national discount factors

$$
\begin{aligned}
& m_{t+1}^{h}=\alpha_{h} g_{t+1}+c_{t+1}^{h} \\
& m_{t+1}^{k}=\alpha_{k} g_{t+1}+c_{t+1}^{k}
\end{aligned}
$$

where $g_{t+1}$ is the global factor and $c^{b}$ and $c^{k}$ are country-specific disturbances orthogonal to $g$.

Define the excess return on currency $k$ over currency $h$ as

$$
r x_{t+1}^{k h}=i_{t}^{k}-i_{t}^{h}-\Delta s_{t+1}^{k h}
$$

This is the (foreign currency $k$ ) return that an investor residing in $k$ will reap from a carry trade strategy that goes short in our home currency $(b)$ and long

2 Since our interest is mainly in short-term fluctuations in the exchange rate, we use the nominal version of this condition, ignoring inflation differentials. 
in his own foreign currency $(k)$. Recognize that the interest rate is given by the negative expected (logarithmic) discount factor:

$$
\begin{aligned}
i_{t}^{h} & \approx-\mathrm{E}\left(m_{t+1}^{h}\right)-\frac{1}{2} \operatorname{var}_{t}\left(m_{t+1}^{h}\right) \\
& =-\alpha_{b} \mathrm{E}\left(g_{t+1}\right)-\mathrm{E}\left(c_{t+1}^{h}\right)-\frac{1}{2}\left[\alpha_{b}^{2} \operatorname{var}_{t}\left(g_{t+1}\right)+\operatorname{var}_{t}\left(c_{t+1}^{h}\right)\right] \\
i_{t}^{k} & \approx-\mathrm{E}\left(m_{t+1}^{k}\right)-\frac{1}{2} \operatorname{var}_{t}\left(m_{t+1}^{k}\right) \\
& =-\alpha_{k} \mathrm{E}\left(g_{t+1}\right)-\mathrm{E}\left(c_{t+1}^{k}\right)-\frac{1}{2}\left[\alpha_{k}^{2} \operatorname{var}_{t}\left(g_{t+1}\right)+\operatorname{var}_{t}\left(c_{t+1}^{k}\right)\right]
\end{aligned}
$$

Lustig, Roussanov and Verdelhan (2009) then sort currencies (at each point in time) into five different portfolios $I=1, \ldots, 5$ by the size of their interest rate differential towards the US dollar. Provided there is a sufficient number of currencies in each portfolio, averaging excess returns across portfolio currencies eliminates the idiosyncratic shocks so that the average excess return on portfolio $I$ is

$$
\begin{aligned}
r x_{t+1}^{I} & =\frac{1}{\# I} \sum_{k \in I}\left(i_{t}^{k}-i_{t}^{h}-\Delta s_{t+1}^{k h}\right) \\
& =\left(\alpha_{b}-\alpha_{I}\right)\left(g_{t+1}-\mathrm{E}\left(g_{t+1}\right)\right)+\frac{\left(\alpha_{b}^{2}-\alpha_{I}^{2}\right)}{2} \operatorname{var}_{t}\left(g_{t+1}\right)-\left(c_{t+1}^{b}-\mathrm{E}\left(c_{t+1}^{b}\right)\right)
\end{aligned}
$$

where $\# I$ denotes the number of currencies in portfolio $I$ and where we denote with

$$
\alpha_{I}=\frac{1}{\# I} \sum_{k \in I} \alpha_{k}
$$

the average loading of the global factor for the currencies in that portfolio. ${ }^{3}$

3 Here we have used that

$$
\sum \Delta s_{t+1}^{k h} / \# I=\left(\alpha_{b}-\alpha_{I}\right) g_{t+1}+c_{t+1}^{b}-\sum c_{t+1}^{k} / \# I
$$

and the two assumptions that

i) $\sum_{k \in I} c_{t+1}^{k} / \# I \rightarrow 0$ for $\# I$ large enough and

ii) that the variances of the idiosyncratic components $c$ are equal across countries. 
Three facts are noteworthy from equation (7). The first is that - since $g$ is uncorrelated with $c$ by assumption - the global factor should only be priced into portfolio $I$ if the home country and the average country in $I$ differ in terms of their exposure to the global factor, i.e. if $\alpha_{b} \neq \alpha_{I}$. Hence, differences in the exposure to the global factor determine the cross-section of currency returns.

Secondly, the difference in exposures, $\alpha_{h}-\alpha_{I}$, is directly linked to the size of the interest rate differential: for a portfolio with sufficiently many currencies, $r x^{I}$ will not depend on $c^{k}$ for $k \neq h$. Therefore, only differences in the loadings of the global factor are left to determine interest rate differentials. Currency portfolios with relatively high interest rates have higher loadings on the global factor.

The third fact is that the above representation allows to make shocks to the global factor (and to its variability) observable. To see this, note that whenever we take the difference in excess returns between two arbitrary portfolios $I_{1}$ and $I_{2}$, the country-specific shock $\left(c_{t+1}^{b}-\mathrm{E}\left(c_{t+1}^{b}\right)\right)$ will cancel out. Specifically, LRV suggest to look at the difference between the portfolio with the highest and the lowest interest rate differential and call this the $H M L^{F X}$ factor:

$$
\begin{aligned}
H M L_{t+1}^{F X} & =r x_{t+1}^{\text {high }}-r x_{t+1}^{\text {low }} \\
& =\left(\alpha_{\text {low }}-\alpha_{\text {high }}\right)\left(g_{t+1}-\mathrm{E}_{t}\left(g_{t+1}\right)\right)+\frac{\left(\alpha_{\text {low }}^{2}-\alpha_{\text {bigh }}^{2}\right)}{2} \operatorname{var}_{t}\left(g_{t+1}\right)
\end{aligned}
$$

which is now free of any country-specific influences. Shocks to this factor are then given by

$$
H M L_{t+1}^{F X}-\mathrm{E}_{t}\left(H M L_{t+1}^{F X}\right)=\left(\alpha_{\text {low }}-\alpha_{\text {bigh }}\right)\left(g_{t+1}-\mathbf{E}_{t}\left(g_{t+1}\right)\right)
$$

so that we obtain a beta-representation for the excess return on portfolio $I$ of the form:

$$
\begin{gathered}
r x_{t+1}^{I}-\mathrm{E}_{t}\left(r x_{t+1}^{I}\right)=\beta_{H M L}^{I}\left(H M L_{t+1}^{F X}-\mathrm{E}_{t}\left(H M L_{t+1}^{F X}\right)\right)-c_{t+1}^{b}+\mathrm{E}\left(c_{t+1}^{b}\right) \\
\text { where } \beta_{H M L}^{I}=\frac{\alpha_{b}-\alpha_{I}}{\alpha_{\text {low }}-\alpha_{\text {bigh }}}
\end{gathered}
$$

In contrast to LRV, in this paper we are interested in studying the exposure of individual currency pairs to global and country-specific factors. Since the interest rate differential for individual currency pairs changes over time, so should the exposure to the global factor. Hence, a fixed beta representation such as (8) 
will not generally exist for individual currency pairs. Rather, the beta for the individual currency pair $k, h$ should be a function of the interest rate differential. We therefore specify

$$
\beta_{H M L}^{k h}(t+1)=\beta_{1}^{k h}\left(i_{t}^{k}-i_{t}^{h}\right)+\beta_{2}^{k b}
$$

which gives us the following time-varying beta representation

$$
r x_{t+1}^{k h}=a+\beta_{1}^{k h}\left(i_{t}^{k}-i_{t}^{h}\right) H M L_{t+1}^{F X}+\beta_{2}^{k h} H M L_{t+1}^{F X}+\beta_{h} c_{t+1}^{h}+\varepsilon_{t+1}
$$

for each currency pair $k, h$ where we include a constant $a$ to capture the compounded effect of the expectation terms, which we assume to be time invariant. We include a residual, $\varepsilon_{t+1}$, to account for any purely idiosyncratic influences on currency pair $k, h$ as well as for possible measurement error (e.g. due to differences in the sampling interval of the interest rate and the exchange rate in our data).

In order to turn this relation into a regression equation, we need an estimate of the idiosyncratic component, $c_{t+1}^{b}$. To obtain this estimate, note that the average excess return of country $h$ vis-à-vis all other $K-1$ currencies is given by

$$
\overline{r x}_{t+1}=\left(\alpha_{b}-\bar{\alpha}\right)\left(g_{t+1}-\mathrm{E}\left(g_{t+1}\right)\right)+\frac{\left(\alpha_{b}^{2}-\bar{\alpha}^{2}\right)}{2} \operatorname{var}_{t}\left(g_{t+1}\right)-\left(c_{t+1}^{b}-\mathrm{E}\left(c_{t+1}^{b}\right)\right)
$$

where $\bar{\alpha}$ is the cross-sectional average of the global factor loadings. LRV assume that the home country has the same loading on the global factor as the average country in the sample so that $\left(\alpha_{b}-\bar{\alpha}\right)=0$. In this case, $\overline{r x}_{t+1}$ directly identifies the country-specific component. Clearly, the assumption $\left(\alpha_{b}-\bar{\alpha}\right)=0$ cannot be satisfied for all countries in the sample unless all countries have the same loading, in which case, however, the global factor would not be priced into currency returns at all. In particular, for a country like Switzerland - a potential safe haven - this assumption would not seem to make sense. We therefore construct the country-specific factor by, in addition, regressing $\overline{r x}_{t+1}$ on $H M L_{t+1}^{F X}$ and its interaction with the interest rate differential. ${ }^{4}$ The residual of this regression

4 Specifically, the domestic factor is the residual of the regression

$$
\overline{r x}_{t+1}^{h}=\alpha+\beta\left(\bar{i}_{t}-i_{t}^{h}\right) H M L_{t+1}^{F X}+\beta H M L_{t+1}^{F X}+\widetilde{r x}_{t+1}
$$

where $\bar{i}_{t}$ is the average of of all foreign interest rates and $H M L_{t+1}^{F X}$ is normalized by its sample standard deviation. 
will be naturally orthogonal to $H M L^{F X}$ and will therefore only contain $c_{t+1}^{b}$. We refer to this orthogonalized country-specific factor as $\widetilde{r x}_{t+1}$. The regression we effectively estimate therefore has the form:

$$
r x_{t+1}^{k h}=a+\beta_{1}^{k h}\left(i_{t}^{k}-i_{t}^{h}\right) H M L_{t+1}^{F X}+\beta_{2}^{k h} H M L_{t+1}^{F X}+\beta_{b} \widetilde{r x}_{t+1}^{b}+\varepsilon_{t+1}
$$

This representation now allows us to address all the issues we wish to study. First, it offers a decomposition of the return on currency pair $k, h$ into a domestic component $\left(\widetilde{r x}_{t+1}^{b}\right)$ and a global component $\left(\beta_{1}^{k h}\left(i_{t}^{k}-i_{t}^{h}\right) H M L_{t+1}^{F X}+\beta_{2}^{k h} H M L_{t+1}^{F X}\right)$. Secondly, the representation of the global component allows for time-varying hedging properties of the currency pair $\left(\beta_{H M L, t+1}^{k b}=\beta_{1}^{k b}\left(i_{t}^{k}-i_{t}^{h}\right)+\beta_{2}^{k b}\right)$, so that the strength of the quantity of aggregate risk associated with a carry strategy in currency pair $k, h$ is directly dependent on the interest rate differential. Conversely, for a given interest rate differential, currencies may still differ in their hedging characteristics because the coefficients $\beta_{1}^{k h}, \beta_{2}^{k h}$ could be different for different countries.

We now apply this framework to the Swiss franc exchange rate. Before we move on to discuss our data set and empirical implementation, some general remarks may help to illustrate the use of the framework.

We conjecture that the role of the Swiss franc as a safe haven has been time-varying. A safe haven currency offers a foreign investor a high return in times of global turbulence. Since $H M L^{F X}$ decreases in bad times and since $r x^{k h}$ is expressed in the foreign investor's $(k)$ own currency, this implies that $\beta_{H M L}^{k h}(t+1)=\beta_{1}^{k h}\left(i_{t}^{k}-i_{t}^{b}\right)+\beta_{2}^{k h}$ should turn positive in bad times. We explore this possibility below.

Note also that the sensitivity of the safe haven property to the interest differential will depend on the slope coefficient $\beta_{2}^{k b}$. For example, in a globally low interest rate environment as we have experienced it over the last decade, interest rate differentials will tend to be very compressed. This may lead a researcher to conclude that the safe haven property of a given currency is no longer apparent or has vanished altogether (see for example Kugler and Weder, 2009). However, it could be that minor changes in interest rate differentials may lead to very different reactions in returns across currencies simply because country pairs differ in the sensitivity coefficient $\beta_{2}^{k h}$. We think that this is one possible way to capture what RANALDO and SÖDERLIND (2008) have called the latent characteristic of the safe haven property. We now turn to our empirical analysis. 


\section{Data}

Our empirical analysis is based on a data set that includes monthly data on nominal interest rates, bilateral spot exchange rates and the global currency risk factor $H M L^{F X}$ for Switzerland, the United States, Canada, Japan, Germany and the United Kingdom. Exchange rates and interest rates are sourced from the July 2009 issue of the IMF's International Financial Statistics. The exchange rates are end of month dollar exchange rates (line 132) and interest rates are end of month money market rates (line 60). We use the global currency risk factor $H M L^{F X}$ as constructed by Lustig, Roussanov and VerdeLHAN (2009). ${ }^{5}$ After having sorted currencies on their interest rate info five portfolios, the $H M L^{F X}$ factor reflects the carry trade return that an US investor gains from going short in the lowest interest rate portfolio and long in the highest interest rate portfolio. ${ }^{6}$ The sample period starts in June 1990 and ends in April 2009.

\section{Empirical Results}

Our theoretical analysis so far has focussed on returns. From a monetary policy perspective however, the interest may be more on medium to longer-term movements in the exchange rate. Figure 1 therefore provides an impression of the cumulative impact of return shocks on the level of the exchange rate. The Figure plots the cumulated average change of the nominal Swiss franc exchange rate against all five major currencies, and compares this to the cumulated changes in the Swiss franc domestic component $\widetilde{r x}_{t+1}$. The difference between the two lines gives an impression to what extent global factors can explain changes in the multilateral Swiss franc nominal exchange rate since the beginning of our sample period. If variation in the exchange rate was driven by the domestic component only, the two lines should be identical. However, as is apparent, there is considerable variation over time in the relative role of global and domestic influences. Whereas in the early part of the period, the exchange rate of the Swiss franc seems to have been explained well by domestic factors, global factors make a huge impact in the late 1990s: as the graph suggests, these global factors pesistently increased the average valuation of the Swiss franc by up to 15 percent relative to the purely domestic component.

5 The data on the global risk factor can be downloaded at http://web.mit.edu/adrienv/www/ CurrencyPortfolios.xls. We use the data on "all currencies".

6 For further details about the construction of currency portfolios see Lustig, Roussanov and VerdelHan (2009). include the following footnote here: 
Figure 1. Multilateral Swiss Franc Exchange Rate versus Domestic Component

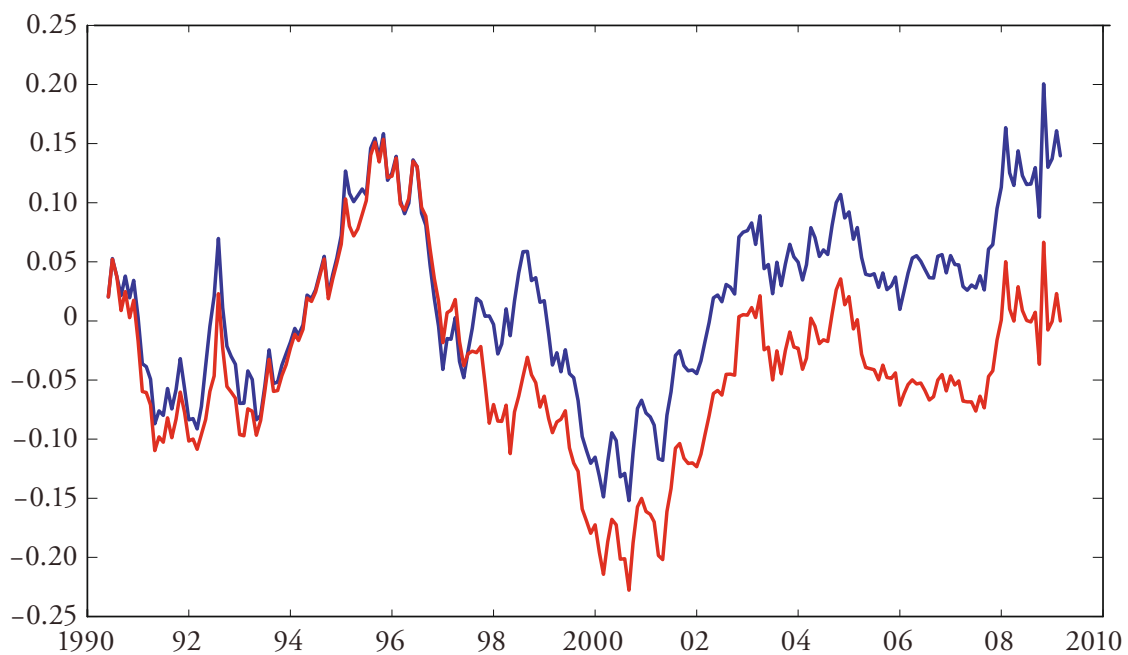

The blue line graphs the cumulated average change of the Swiss franc exchange rate against all five major currencies. The red line graphs the cumulated change of the Swiss franc domestic component $\widetilde{r x}_{t+1}$.

Figure 2 shows the impact of the global factor $H M L^{F X}$ on the return of a portfolio that goes short in Swiss franc and long (in equal weights) in all the other major currencies. From the way in which $\tilde{r x}$ was constructed, recall that the difference between $\overline{r x}$ and $\widetilde{r x}$ gives this impact of the global factor, weighted with the average interest rate differential across all currencies:

$$
\overline{r x}_{t+1}-\widetilde{r x}_{t+1}=\beta_{1} H M L_{t+1}^{F X}+\beta_{2}\left(\overline{i_{t}}-i_{t}^{b}\right) H M L_{t+1}^{F X}
$$

where $\bar{i}$ is the average interest rate in the other countries. In this graph, starting in 1990:6, we also indicate a sequence of major geopolitical events, natural disasters and economic crises that we take and update from RANALDO and SöDERLIND (2008). As is clearly apparent, $\overline{r x}-\widetilde{r x}$ experiences strong negative shocks during some events but not during all. For example, the reaction to September 11 th and other geopolitical and natural disaster events is relatively muted, whereas there is a strong reaction during economic crises, notably the Asian crisis and its 
aftermath (including the Russian default and LTCM), the 2000 stock market crash. The franc also loads on the global shocks of the recent sub prime crisis (Bear Stearns, Freddie Mac/Fannie Mae, Lehman Brothers), but the effect is dwarfed by the events of the late 1990s. In all these economic events, however, a carry trade portfolio short in Swiss francs would have done very badly, suggesting that the Swiss franc has indeed played a role as a safe haven in the aftermath of these events.

Figure 2: Average Global Return Component and Global Events

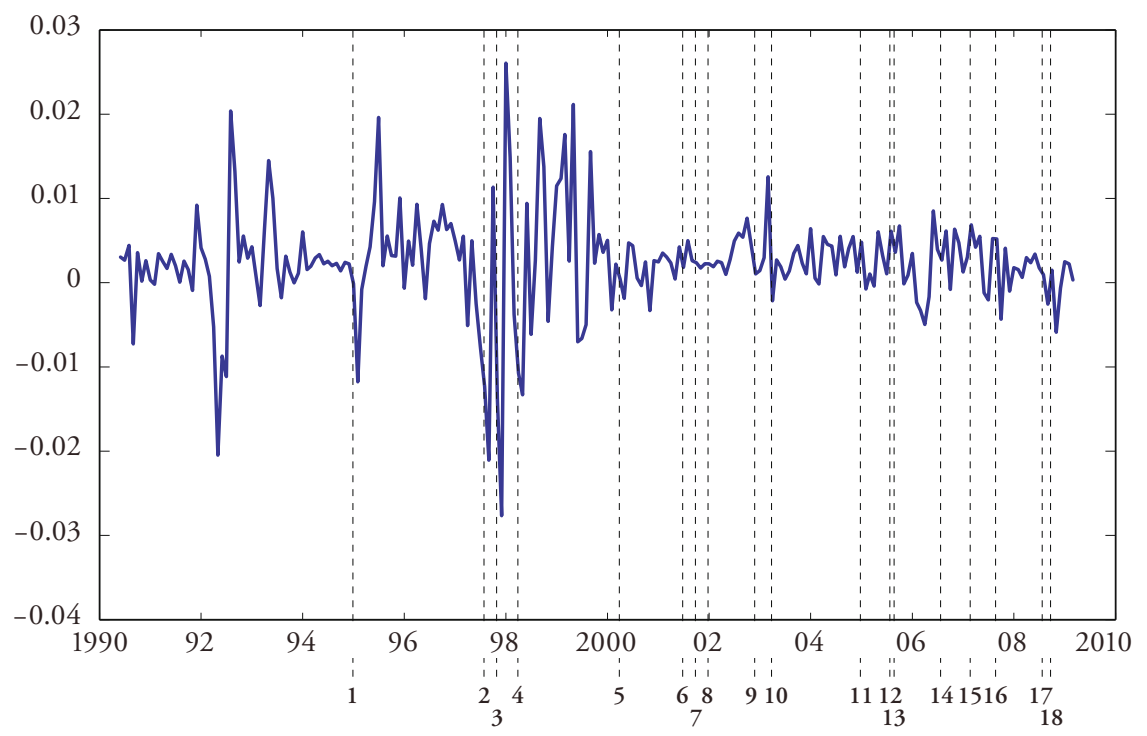

The blue graph is the global return component, constructed as described in the text:

$$
\left(r x_{t+1}-\widetilde{r x}_{t+1}\right)=\beta_{1}\left(\bar{i}_{t}-i_{t}^{b}\right) H M L_{t+1}^{F X}+\beta_{2} H M L_{t+1}^{F X} .
$$

The dashed vertical lines mark the global events listed below.

1: Tequila peso crisis (1994:12) 2: East Asian Financial Crisis (1997:07) 3: Global stock market crash (1997:10) 4: Russian financial crisis (1998:03) 5: Dot-com bubble burst (2000:03) 6: 2001 Atlantic hurricane (2001:06) 7: WTC terrorist attacks (2001:09) 8: Accounting scandals (Enron) (2001:12) 9: SARS (2002:11) 10: Second Gulf War (2003:03) 11: Tsunami (2004:12) 12: London bombings (2005:07) 13: Hurricane Katarina (2005:08) 14: Lebanon War (2006:07) 15: Sell-off of Chinese shares (2007:02) 16: Bear Stearns bankruptcy (2007:08) 17: Total write downs on MBS reach 435 billion US-\$, Indy Mac failure, Freddie and Fannie in crisis, Housing and Economic Recovery Act (2008:07) 18: Lehman Brothers bankruptcy (2008:09). 
Figure 3: Bilateral Exchange Rate versus Cumulated Global Component
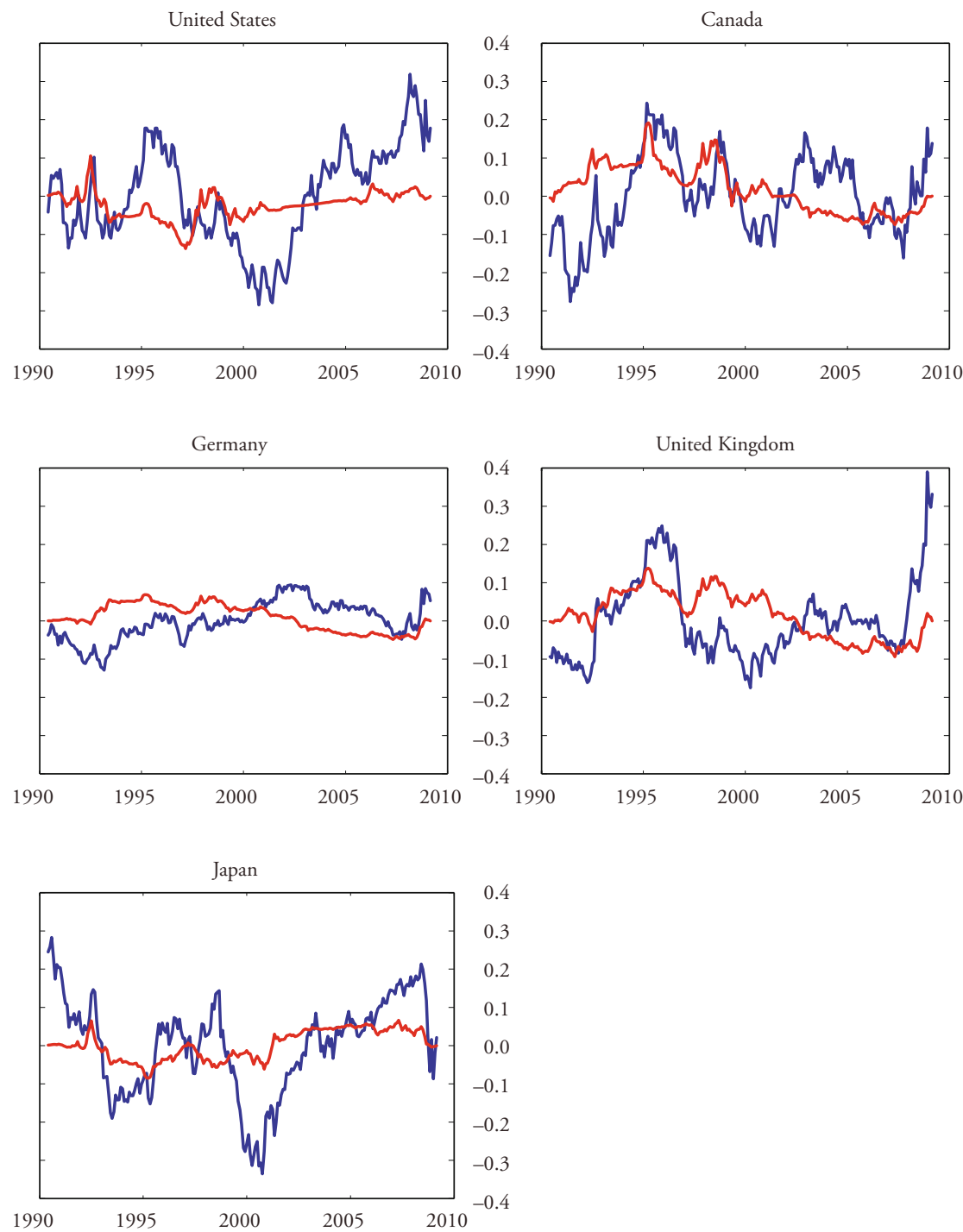

The blue line graphs bilateral spot exchange rates as deviations from their mean, the red graph plots the cumulated deviation of the global component from its mean. The global component is the fitted values of the global part in our baseline regression (1):

$$
\beta_{1}^{k h}\left(i_{t}^{k}-i_{t}^{h}\right) H M L_{t+1}^{F X}+\beta_{2}^{k h} H M L_{t+1}^{F X} .
$$


Figures 1 and 2 mask considerable differences across currency pairs. This becomes clear from Figure 3 which looks at the role of the global component in explaining departures of bilateral exchange rates from their mean. The global component plotted in this figure is the cumulated deviation of the fitted global part of our baseline regression (14) from its mean. The exchange rates vis-àvis Canada, the UK and Japan seems most clearly explained by global factors. Given that both the Swiss franc and the yen are preferred funding currencies in the global carry trade, it may not be surprsing that in particular the yen-franc exchange rate should be very sensitive to fluctuations in global conditions. The Swiss franc US dollar exchange rate seems strongly influenced by global factors in the first half of our sample period but much less so in the last decade. The same is true for the Deutschmark (euro) exchange rate which could be a signal of the rising role of the euro as a reserve and safe haven currency itself.

Figure 4, quite in analogy to Figure 2, gives the global component for individual currency returns. Again it is the case that most major crisis events load very differently on different currency pairs. For example, the reaction of the exchange rate vis-à-vis the US dollar to the 2007/2008 financial crisis seems relatively muted. The same is true for the euro-to-franc exchange rate which hardly seems to react to global shocks at all. Conversely, the crisis loads much more heavily on the bilateral exchange rate vis-à-vis the yen and sterling.

The first column of Table 1A reports the results for the baseline regression (14) for the period 1990:6 till 2009:4. In addition, the global factor is normalized by its sample standard deviation. Note first that the domestic factor is significant throughout, even though the exposure of individual currency pairs again varies a lot across countries. More importantly, the beta on the interaction between the interest rate and the global factor, $H M L^{F X}$, is highly significant and positive for Switzerland vis-à-vis the US and Canada. This suggests that a low interest rate in Switzerland would indeed be indicative of the Swiss franc acting as safe haven for investors based in these countries.

Conversely, the estimate of $\beta_{1}^{k b}$ is insignificant vis-à-vis Germany/the euro, the United Kingdom and Japan, suggesting that the interest rate differential does not provide a strong signal as to the safe haven properties of the franc vis-à-vis these currencies. However, the UK is the only country for which $\beta_{2}^{k b}$ is positively significant, i.e. it is the only country for which a safe haven property seems apparent independently of the interest rate differential.

While we have seen that a low interest rate on the Swiss franc indicates that the Swiss franc serves as a hedge vis-à-vis at least some of these currencies (notably the dollar), the role of the franc is not unique in this respect. Columns 2-5 of Table 1A provide the results of our basic regression when the other countries 
Figure 4: Global Return Components and Global Events
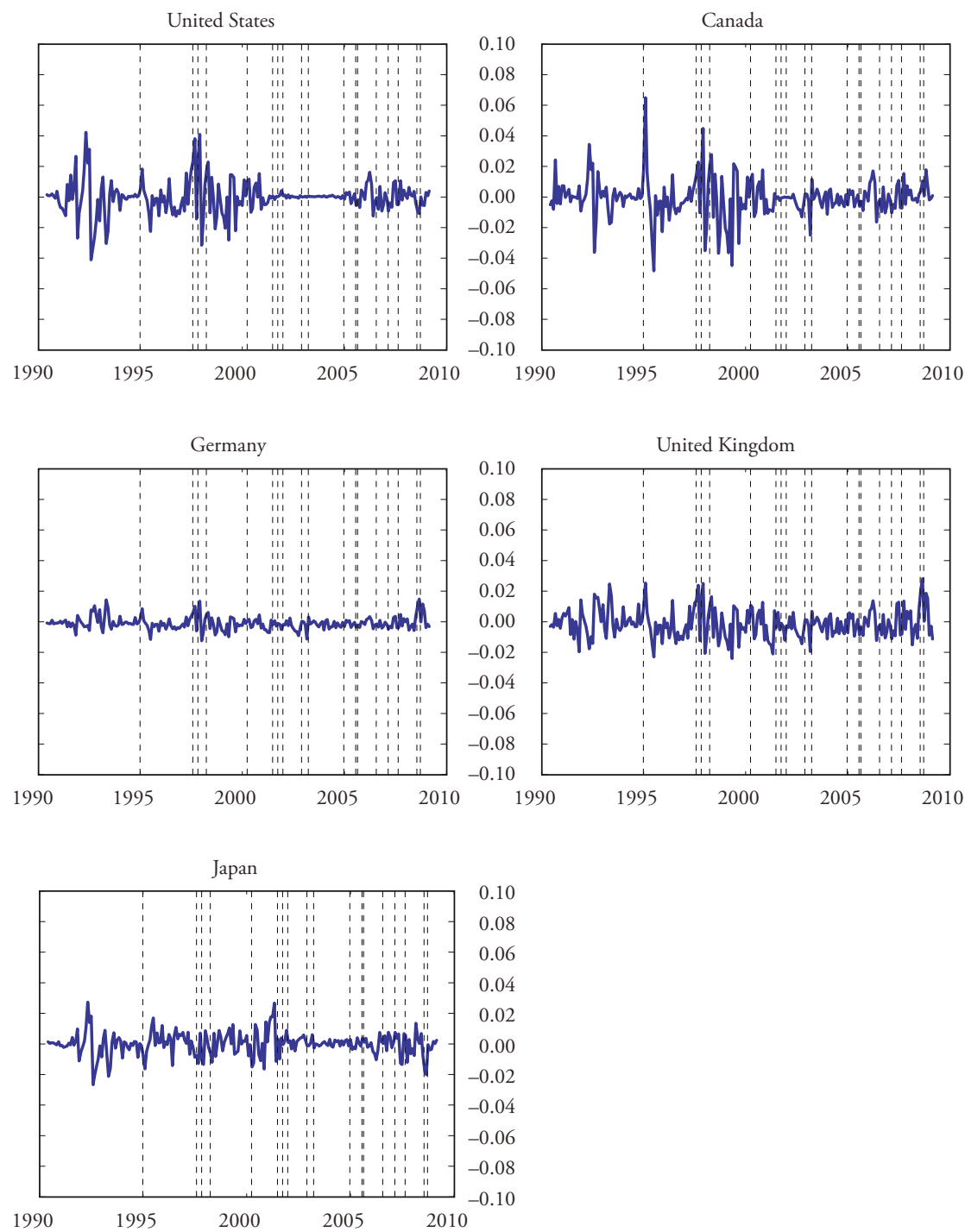

The blue graph plots the global component as described in the notes of Figure 3, the dashed vertical lines mark the same global events as described in the notes of Figure 2. 
are used as the reference countries. As is apparent, $\beta_{1}^{k h}$ is significant and positive in a number of cases, notably for the euro-to-US-dollar exchange rate, the pound/dollar and the Canadian dollar vs. the euro.

The results in Table $1 \mathrm{~A}$ suggest that the safe haven property is a) a priori a feature of individual currency pairs rather than of an individual currency, and $b$ ) that the safe haven property is time varying with the interest rate differential acting as a powerful indicator for the strength and sign of the exposure to the global factor. This latter observation has an important implication for the detectability of safe haven behaviour: in an environment with globally low interest rates, interest rate differentials will also be small and the safe haven effect may appear very subdued - even in periods of increased global volatility. In the context of our model, the rationale for this pattern is simple: for a foreign investor, the hedging characteristics of a currency depends on how different the country's exposure to global shocks is from that of other countries, and the interest rate differential is an indicator of this exposure differential. If the expected exposure to global shocks differs little across countries, then safe haven behaviour in individual currency pairs should not be very strong. However, it may still be the case that former patterns of safe haven behavior manifest themselves again, once international differences in the exposure to global shocks start to widen.

To show that what we are picking up in our baseline regression is really related to variation in exchange rates (and therefore to currency risk) and not to some correlation between the interest rate differentials, Table $1 \mathrm{~B}$ repeats the exercise from Table $1 \mathrm{~A}$, but now with the negative of bilateral exchange rate changes, $-\Delta s_{t+1}^{k, h}$, as the dependent variable. The results stay qualitatively very much the same: the sensitivity to the interest rate differential is significant and positive for the US, Canada, almost significant for Japan and insignificant for the UK and Germany. For the UK, however, $\beta_{2}^{\text {bk }}$, the average level of exposure, is significantly positive.

As we have argued before, the time-varying beta with respect to $H M L^{F X}$

$$
\beta_{H M L}^{k h}(t+1)=\beta_{1}^{k h}\left(i_{t}^{k}-i_{t}^{b}\right)+\beta_{2}^{k h}
$$

can be interpreted as a safe haven index: in periods when $\beta_{H M L}^{k h}(t+1)$ is positive, the franc is a safe haven for country $k$ investors, when it is negative, foreign investors buy additional global risk with their Swiss franc investment. We plot this index in Figure 5, based on the estimates of $\beta_{1}^{k b}$ and $\beta_{2}^{k b}$ from Table 1A. Over the sample period, exposure to the global factor has varied most strongly vis-à-vis the US and Canadian dollars and the yen. For these countries, the index actually also changes sign, indicating that the role of the Swiss franc as a safe haven 


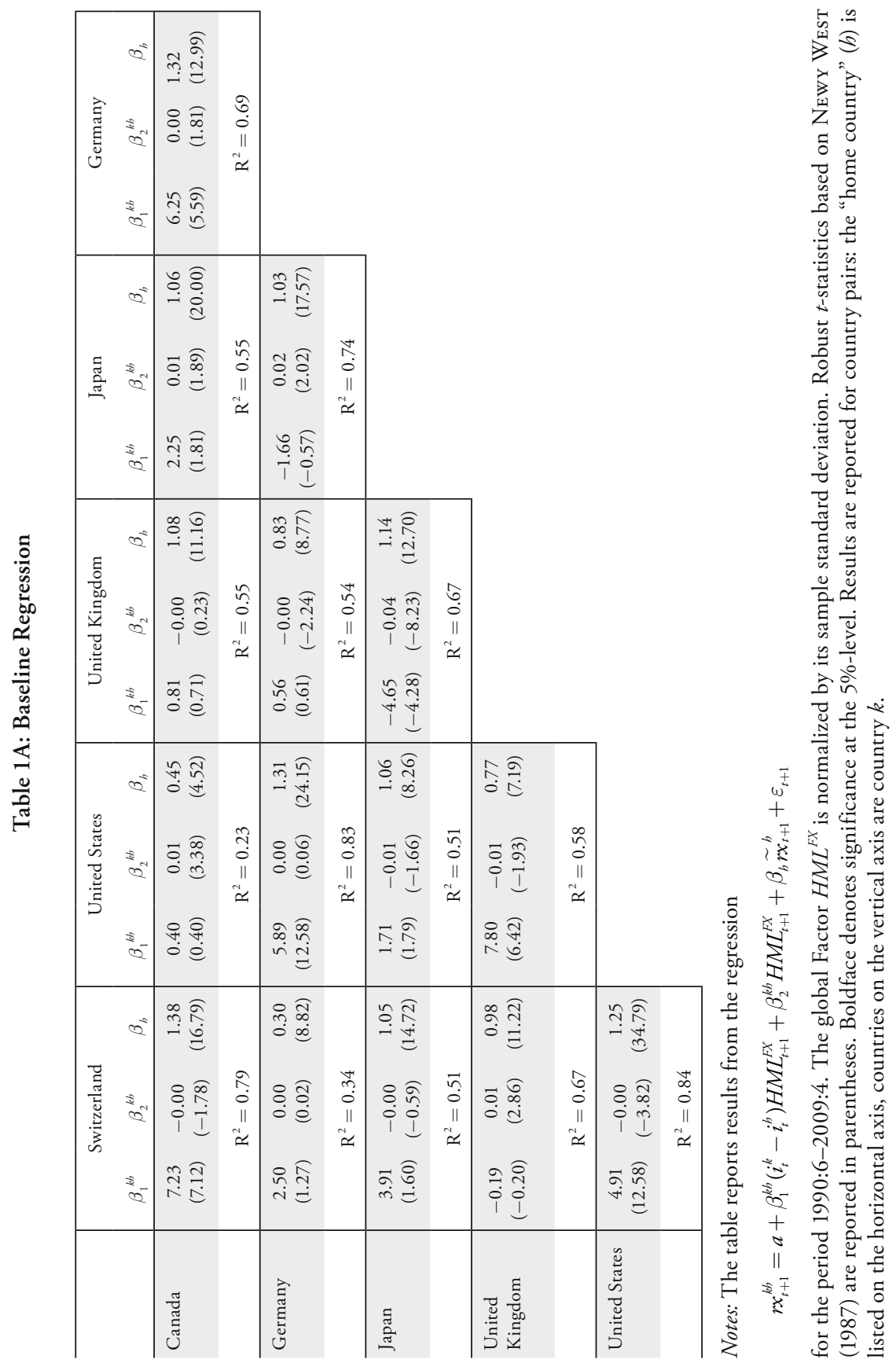




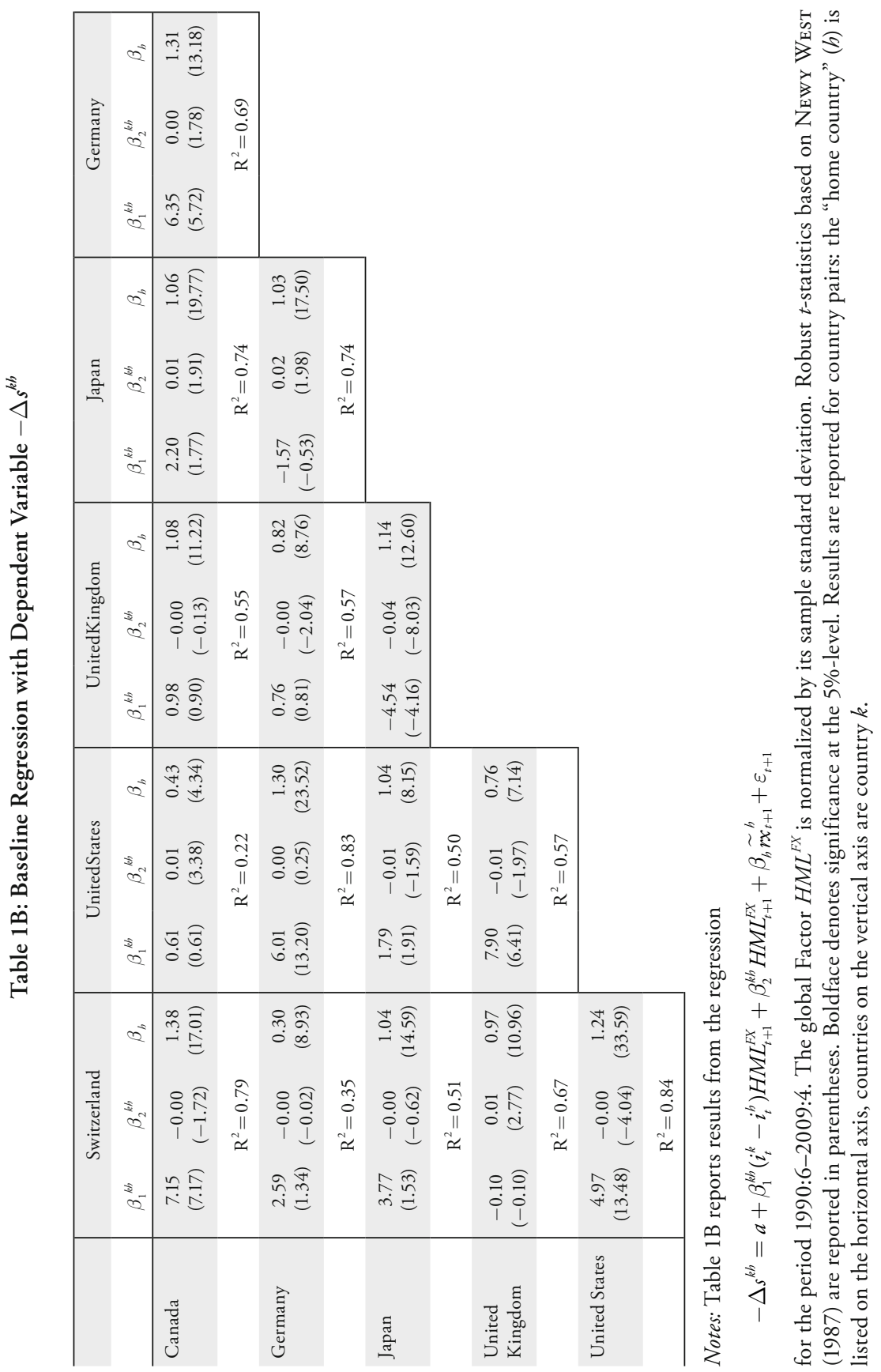


Figure 5. Bilateral Safe Haven Index and Global Events
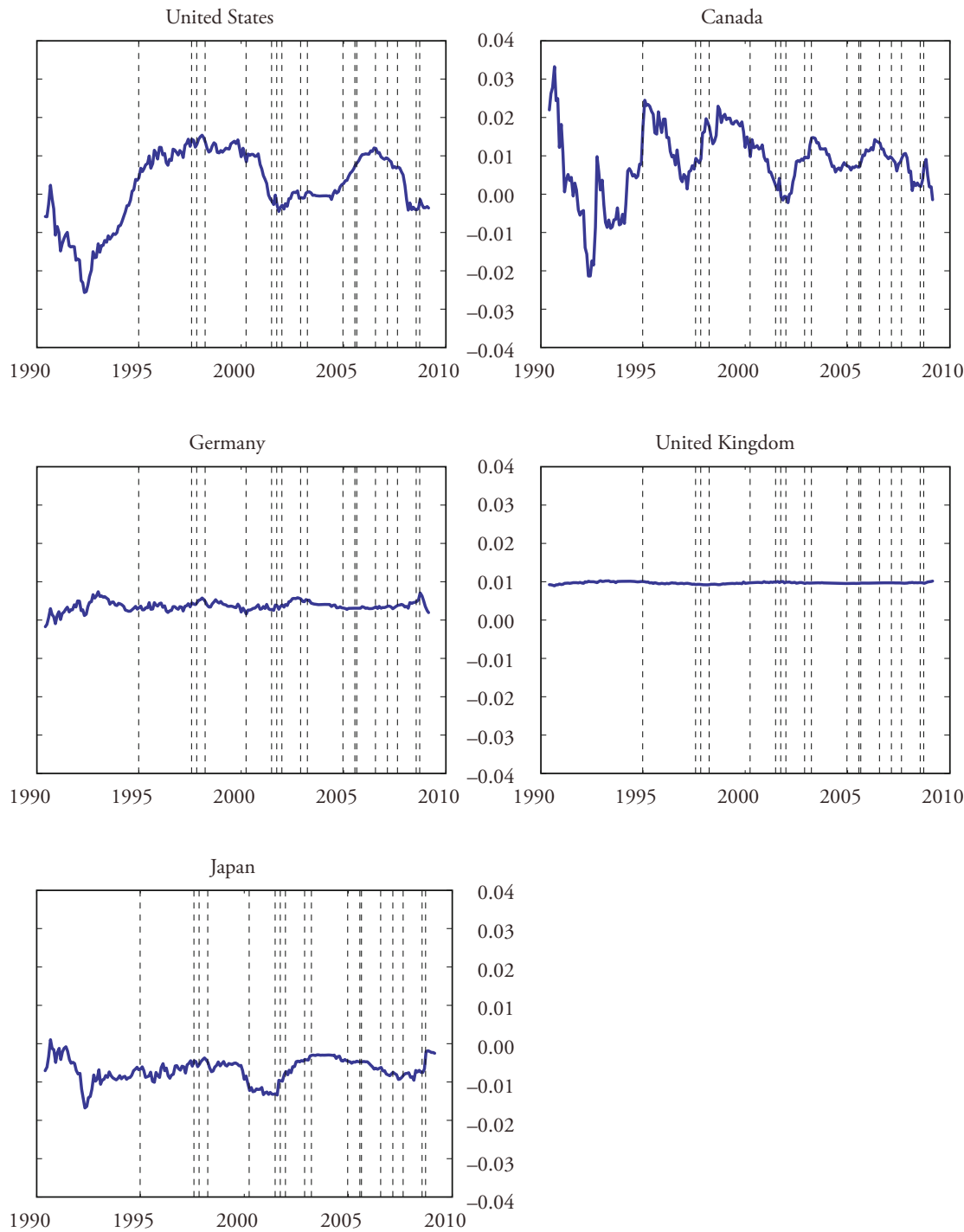

The blue graph plots the save haven index $\beta_{H M L}^{k h}(t+1)=\beta_{1}^{k h}\left(i_{t}^{k}-i_{t}^{h}\right)+\beta_{2}^{k h}$, where $\beta_{1}^{k h}$ and $\beta_{2}^{k h}$ are the estimated regression coefficients of the baseline regression in Table 1A. The dashed vertical lines mark the global events described in the notes of Figure 2. 
is actually time varying. Vis-à-vis the yen, the index is actually negative for most of the period. For both Germany and - to a somewhat lesser extent - the UK the index is much more stable. For both of these economies it is also positive throughout but generally close to zero.

\subsection{Extensions and Robustness: Market Volatility and Other Pricing Factors}

One important extension of our result here is to allow the volatility of $H M L^{F X}$ to vary over time. Note from equation (8) that $H M L^{F X}$ depends on the volatility of the global factor $g$. Changes in $\operatorname{var}\left(g_{t+1}\right)$ will therefore directly affect $H M L_{t+1}^{F X}$ and visual inspection, e.g. of Figure 2, suggests that the volatility of $H M L^{F X}$ may indeed have been varying over time. We explore possible implications of this observation next.

As a first exercise, we estimate a GARCH process for $H M L^{F X}$ and included the ensuing fitted volatility - to which we refer as $h^{2}$ - as a third pricing factor into our model (besides $H M L^{F X}$ and its interaction with the interest rate differential). The factor $h^{2}$ is never significant and the coefficients on $H M L^{F X}$ and the interaction with the interest rate differential remain largely unchanged vis-à-vis our baseline specifications.

As a second exercise, we run a regression of $H M L^{F X}$ on $h^{2}$. Note from equation (8) that if $h_{t}^{2}$ is a proxy of $\operatorname{var}_{t}\left(g_{t+1}\right)$, then the fitted value of this regression corresponds to $\mathrm{E}_{t}\left(H M L_{t+1}^{F X}\right)$ and the residual identifies the global shock, $H M L_{t+1}^{F X}-\mathbf{E}_{t}\left(H M L_{t+1}^{F X}\right)$. We therefore use this residual (instead of $H M L^{F X}$ itself) in our conditional-beta specification (14). Again, the results are similar to the ones obtained from the baseline specification.

Note that these findings do not imply that $h^{2}$ is constant. Quite to the contrary - the volatility of $H M L^{F X}$ is time-varying and displays a positive correlation with extant volatility indexes. Our discussants (ManCini Griffoli (2010) and Ross (2010), both this issue) have more to say on this point and we agree with most of their suggestions. What we can conclude from the exercises here, however, is that explicitly modelling the time-variation in $b^{2}$ does not help improve the identification of shocks to $g$ very much: while changes in volatility may be predictable, they may simply not be predictable enough to substantially affect the identification of shocks to the global discount factor. That does not mean, that the shocks themselves - which are the relevant aspect from an asset pricing perspective - are homoskedastic or that these shocks may not in part represent volatility shocks. At a more general level, it is therefore important to acknowledge that measures of market volatility and many other plausible pricing factors that one may want to include in the empirical specifications for currency risk can be 
nested as special cases within the current framework. The reason for this is that the theoretical foundations for $H M L^{F X}$ are parsimonious but very strong, since they rest on only two assumptions: a) that markets are complete and b) that interest rates reflect the inverse of the expected discount factor. Clearly, if any of these two assumptions is violated, then other factors may be priced independently of $H M L^{F X}$. As our discussants suggest, liquidity risk factors (the very presence of which would imply that markets are incomplete) may be one important candidate - specifically against the backdrop of the recent financial crisis.

\section{Discussion and Conclusion}

In a small open economy, medium-term exchange rate fluctuations can have a direct bearing on domestic inflation. Monetary policy may therefore want to offset some shocks to the exchange rate. This objective may be harder to achieve if such shocks are largely global in origin. It is therefore important to ask to which extent fluctuations in exchange rates are determined by global and domestic factors. While interesting at a general level, this question attains particular relevance in the context of the Swiss franc exchange rate. For the last 70 years, returns on debt assets denominated in Swiss francs have experienced a much lower return than similar assets in other major currencies. While such violations of uncovered interest parity (UIP) abound in the data for virtually all currencies, it is the persistence of this violation in Swiss data that is striking. This stylized fact has been dubbed the 'Swiss interest rate puzzle' (Kugler and Weder, 2009) and is often ascribed to an inverse peso problem, i.e. an alleged safe haven property of the Swiss franc. But the very notion of safe haven implies that movements in the nominal exchange rate are dominated by global shocks in terms of crisis. In this paper, we have proposed a novel way to identify such global factors in the data.

Our analysis is based on the methodology pioneered by Lustig, RoussaNOV and VERDELHAN (2009). The key insight underlying this approach is that exchange rates reflect relative movements in national discount factors. Simple asset pricing theory would then predict that systematic excess returns on a currency can only be explained by international differences in the exposure to the common component of all national discount factors. Here, we have extended this methodology to allow individual currencies' exposure to vary over time as a function of the interest rate differential. Based on this approach, we have then identified global and domestic components in returns on assets denominated in Swiss franc. We also have assessed the cumulative impact of these components on the level of the exchange rate. Our main results are as follows: 
Indeed, the Swiss franc has a tendency to appreciate in times of global economic turbulence, but this statement requires several qualifications:

First, the size of global components differ a lot across currency pairings and over time. For example, in the recent crisis, the global component has played an important role for bilateral exchange rate movements vis-à-vis the yen, the pound and the Canadian dollar but - maybe surprisingly - much less vis-à-vis the US dollar. Over the last ten years, there is also virtually no global exposure in the bilateral euro/franc exchange rate which could partly be explained by the rise of the euro as an international currency with similar hedging qualities as the franc or with the increased integration of Switzerland into the European economy. Both developments could have contributed to dampening differences in the exposure to global shocks between the EMU and Switzerland.

Secondly, the strength of the safe haven characteristics is strongly dependent on the size of the interest rate differential, most strongly so vis-à-vis the US and Canada. The last ten years have seen a tendency for interest rate differentials to become more compressed between the major currencies, reflecting the globally low interest rate environment and the continued moderation in macroeconomic volatility. In return, the safe haven property of the classical low interest rate currency Swiss franc may have appeared rather subdued as compared with earlier periods. We argue, however, that this does not imply that the safe haven property - and with it the Swiss interest rate island - is necessarily gone for good. In fact, we document that global factors have proven to be very persistent in terms of their effect on the level of the exchange rate and have led to a considerably higher average valuation of the Swiss franc vis-à-vis an equally-weighted basket of major currencies than would have been justified based on purely country-specific influences. We also document that the sensitivity of the exposure to global factors to changes in the interest rate differential still differs a lot across currencies. This suggests that return characteristics of major currencies may diverge again in a situation where global shocks lead to very different responses in national discount factors. The appreciation of the franc in the recent crisis seems to support this view - the Swiss interest rate island may only have temporarily disappeared and may well resurface in the ebb and flow of global economic conditions.

7 The paper was completed well before the breakout of the Greek sovereign debt crisis. In future work it will be interesting to assess whether the associated depreciation of the euro against the Swiss franc reflects a largely idiosyncratic shock or rather the difference in the exposure of the two currencies to the global factor. 


\section{References}

Backus, David K., and Gregor W. Smith (1993), "Consumption and Real Exchange Rates in Dynamic Exchange Economies with Nontraded Goods", Journal of International Economics, 35(3-4), pp. 297-316.

Engel, Charles M. (1996), "The Forward Discount Anomaly and the Risk Premium: A Survey of Recent Evidence”, Journal of Empirical Finance, 3, pp. 123-192.

Kugler, Peter, and Beatrice Werder (2002), "The Puzzle of the Swiss Interest Island: 'Stylized Facts and a New Interpretation'”, Aussenwirtschaft, 57, pp. 49-63.

Kugler, Peter, and Beatrice Werder (2004), "International Portfolio Holdings and Swiss Franc Returns", Schweizerische Zeitschrift für Volkswirtschaft und Statistik, 140, pp.301-325.

Kugler, Peter, and Beatrice Werder (2005), "Why are Returns on Swiss Franc Asset so Low?”, Applied Economics Quarterly, 51(3), pp. 231-246.

Kugler, Peter, and Beatrice Werder (2009), “The Demise of the Swiss Interest Rate Puzzle", SNB-IMF Conference on Exchange Rates.

Lenz, Carlos, and Marcel Savioz (2009), "Monetary Determinants of the Swiss Franc", paper presented at the annual conference of the Swiss Society of Economics and Statistics, Lausanne 2009.

Lustig, Hanno, and Adrien Verdelhan (2007), "The Cross Section of Foreign Currency Risk Premia and Consumption Growth Risk", American Economic Review, 97(1), pp. 89-117.

Lustig, Hanno, Nick Roussanov and Adrien Verdelhan (2009), "Common Risk Factors in Currency Markets", Finance International Meeting AFFIEUROFIDAI, Paris, December 2008. Available at SSRN: http://ssrn.com/ abstract $=1139447$.

Newey, Whitney K., and Kenneth D. West (1987), "A Simple, Positive Definite, Heteroskedasticity and Autocorrelation Consistent Covariance Matrix", Econometrica 55(3), pp. 703-708.

Ranaldo, Angelo, and Paul Söderlind (2007), "Safe Haven Currencies", Swiss National Bank Working Papers, 17.

Roth, Jean-Pierre (2008), "The Exchange Rate and Swiss Monetay Policy", address to the SNB-CEPR conference Foreign Currency Related Risk Taking by Financial Institutions, Firms and Households, Zurich, September 22, 2008. 


\section{SUMMARY}

We examine the role of global and country-specific factors for the Swiss franc exchange rate in the period 1990-2009. Simple asset pricing theory would predict that exchange rates reflect relative movements in national discount factors and that systematic departures from uncovered interest parity can only be explained by international differences in the exposure to the common (global) component of all national discount factors. We extend the methodology of Lustig, RousSANOV and VeRDELHAN (2009) to allow individual currencies' exposure to this global factor to vary over time as a function of the interest rate differential. This allows us to study the time-varying risk characteristics of individual currency pairs. We find that the Swiss franc acts as a safe haven against some currencies notably for dollar-based investors - but not for all, specifically not the euro. Also, the extent to which global factors have weighed on the Swiss franc exchange rate has varied over the sample period and appears more subdued in the global low interest rate environment of the last decade. 